\title{
Solitary eosinophilic granuloma of the lumbar spine in an adult. Case report
}

\author{
T Bilge $^{1}$, Ş Barut ${ }^{1}, \mathrm{Y}$ Yaymaci $^{1}$ and C Alatli ${ }^{2}$ \\ ${ }^{1}$ Department of Neurosurgery, Taksim Hospital, Istanbul; ${ }^{2}$ Department of Pathology, Oncology Institute of \\ Istanbul, University Istanbul, Turkey
}

\begin{abstract}
Eosinophilic granuloma of bone is the localised and most benign form of Langerhans-cell histiocytosis, previously known as histiocytosis $\mathrm{X}$ and is characterised by lytic lesions of one or more bones. It is a disease of children and adolescents, and very rarely affects adults. We report a 34-year-old patient with a solitary eosinophilic granuloma involving the fifth lumbar vertebra which produced sciatica. Operative treatment performed by a single extended posterior approach consisted of total resection of the tumour with hemicorporectomy, L4-5 and L5-S1 discectomy, interbody fusion with an iliac bone graft, and interpedicular fixation. Postoperatively, the symptoms resolved and the patient continues to do well at $2 \frac{1}{2}$ years follow-up.
\end{abstract}

Keywords: solitary eosinophilic granuloma; Langerhans cell histiocytosis; lumbar spine; spinal tumour

\section{Case report}

A 34-year-old female was admitted to hospital with a 3-month history of low back pain radiating down the left leg to the foot. The pain gradually increased in intensity and became continuous. It was aggravated by coughing and straining. There was no history of trauma, and her past medical and family histories were non-contributory. On clinical examination, she was afebrile and had a positive straight leg raising test on the left at $40^{\circ}$. Palpation revealed diffuse tenderness over the lumbar spine without point tenderness. A full blood count, urinalysis, and the sedimentation rate were normal. Radiography of the lumbar spine was normal. A CT scan of the lumbar spine showed an L5 lesion eroding the vertebral body (Figure 1). A bone scan and chest/abdominal CT scans were normal. A diagnosis of benign bone tumour of the spine was suspected with the differential diagnosis including aneurysmal bone cyst and solitary plasmacytoma. Surgery was performed using a posterolateral approach and included total resection of the tumour with hemicorporectomy, with the aid of an ultrasonic surgical aspirator, discectomy of L4-5 and L5-S1, and then bone replacement with an autologous iliac graft. Thus there was decompression of the spinal canal and foramina. Interpedicular fixation was performed (Figure 2). The biopsy material was sent to the pathology department of Istanbul University, Institute of Oncology, for histopathological diagnosis, and sections were stained with hematoxylin and eosine. They were studied, and showed vascular connective tissue infiltrated with eosinophilic granulocytes, lymphocytes and histiocytes (Figure 3). In some areas multinucleated histiocytic giant cell were observed. The diagnosis was that of an eosinophilic granuloma. Postoperatively, the sciatica resolved, and the patient continues to do well at $2 \frac{1}{2}$ years follow-up.

Correspondence: \$̧ Barut, Nöroşirürji Kliniği, Taksim Hastanesi, Taksim, Istanbul, Turkey

\section{Discussion}

Eosinophilic granuloma $(\mathrm{EG})^{1-3}$ of bone is a relatively uncommon disease accounting for less than $1 \%$ of all bone tumours, and it primarily involves the skull, pelvis, ribs and long bones. ${ }^{4}$ Involvement of the spine is reported to occur in approximately $10 \%$ of cases, most often affecting the thoracic and least often, the cervical and lumbar spine..$^{5-13} \mathrm{EG}$ of bone primarily afflicts children and adolescents, with up to $80 \%$ of patients presenting before the age of $10 .{ }^{14}$ In an adult, the presentation of EG as a solitary vertebral lesion producing neurological deficit is uncommon. ${ }^{15-18}$

In children, EG of the spine usually results in complete collapse of the vertebral body. In adults, however, relatively small areas are affected, and EG is not associated with vertebral collapse. ${ }^{5,6,19}$ Thus, the roentgonographic picture is not characteristic when there is an EG of vertebral lesion without vertebral body collapse. Since the introduction of computed tomography $(\mathrm{CT})$, and more recently magnetic resonance imaging (MRI), the diagnoses of these tumours have unexpectedly increased. ${ }^{20-22}$ The differential diagnosis includes aneurysmal bone cyst, Gaucher's disease, acute leukaemia, metastatic neuroblastoma, and Ewing's sarcoma. ${ }^{23-26}$

Pain is the most common presenting symptom of EG, especially for lesions of the lumbar spine. The duration of symptoms prior to diagnosis generally ranges from a few weeks to months. There is often a history of trauma. Rapid bone destruction has been reported with vertebral collapse occurring during a 3-week interval of observation. Neurological deficits have rarely been reported to occur and are thought to be caused by impingement of the spinal neural elements secondary 


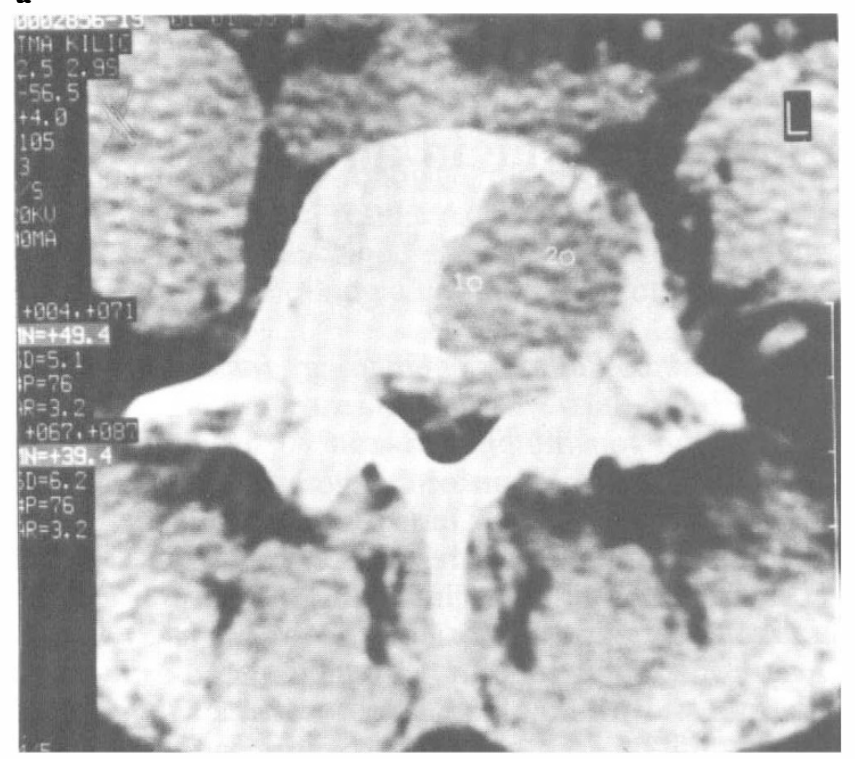

b



Figure 1 ( $a$ and b) Preoperative axial and sagittal CT scans showing an irregularly shaped osteolytic destructive lesion within the body of L5, extending into the spinal canal and neural foramen

to vertebral collapse or from peridural spread. $5,7,8,10-13$ Our patient had no history of trauma and suffered from nerve root impingement from peridural spread.

Treatment of EG is dependent upon the extent of disease, and includes extirpation of the tumour, stabilisation of the spine, and preservation/restoration of neurological function. Most experts recommend that unifocal disease should be treated with complete excision of the tumour, whenever possible. ${ }^{1,19}$ Surgery may involve a multistage, combined anterior and posterior approach, or a single extended posterior approach, as in our patient. Previously, the arrest of vertebral collapse following radiation therapy has been reported. ${ }^{9}$ But many authors have stated that radiation therapy did not affect the natural history of solitary



b

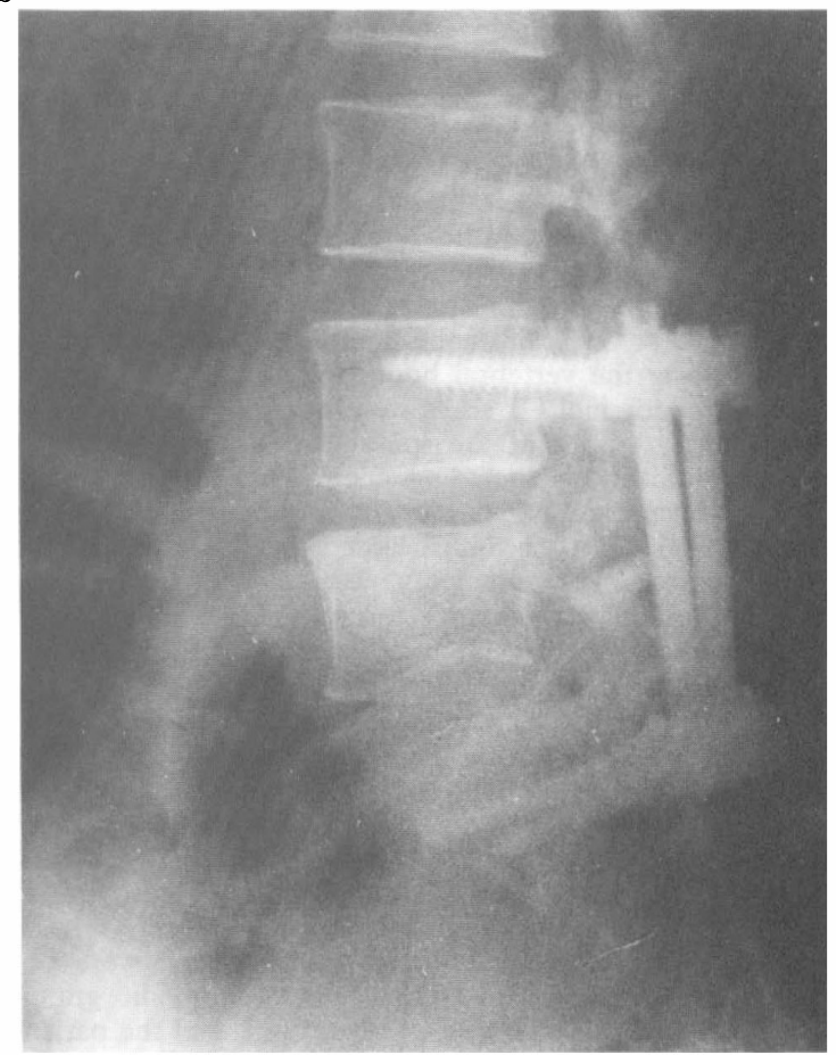

Figure 2 (a and b) Plain radiographs taken 6 months following surgery which included interbody autologous graft implantation and posterior instrumentation 




Figure 3 Histological study, showing numerous histiocytes, eosinophilic granulocytes together with lymphocytic infiltrations within a vascular stroma $(\mathrm{H}+\mathrm{E}, \times 250)$

EG. ${ }^{18,19,26}$ Two and a half years after our patient's surgical procedure there was no detection of tumour recurrence, and a stable fusion was observed, even although radiotherapy was not used postoperatively. In summary, we suggest that an EG should be considered in the differential diagnosis of a vertebral body tumour and the management of spinal EG should include detailed imaging and a tissue diagnosis. In patients with evidence of impending neurological compromise or instability, surgical intervention is recommended. There is no clear evidence that radiation therapy is of benefit for solitary EG.

\section{References}

1 Mickelson MR, Bonfiglio M. Eosinophilic granuloma and its variations. Orthop Clin North Am 1977; 8: 933-945.

2 Schajowicz F, Slullitel J. Eosinophilic granuloma of bone and its relationship to Hand-Schuller-Christian and Lettere-Siwe syndromes. J Bone Joint Surg Br 1973; 55: 545-565.

3 Writing Group of the Histiocyte Society. Histiocytosis syndromes in children. Lancet 1987; 1(8526): 208-209.

4 Rawlings CE III, Wilkins RH. Solitary eosinophilic granuloma of the skull. Neurosurgery 1984; 15: 155-161.

5 Sweasey T, Dauser RC. Eosinophilic granuloma of the cervicothoracic junction. J Neurosurg 1989; 71: 942-944.
6 Nesbit ME, Kieffer S, D'Angio GJ. Reconstitution of vertebral height in histiocytosis X: A long-term follow-up. J Bone Joint Surg Am 1969; 51: 1360-1367.

7 Farine I et al. Granulome eosinophiles vertebraux avec compression medularie chez l'enfant. Rev Chir Orthop 1972; 58: 575-586.

8 Salcman M, Quest DO, Mount CA. Histiocytosis X of the spinal cord: case report. J Neurosurg 1974; 41: 383-386.

9 Green NE, Robertson WW Jr, Kilroy AW. Eosinophilic granuloma of the spine with associated neural deficit: Report of three cases. J Bone Joint Surg Am 1980; 62: 1198-1202.

10 Gandolfi A. Vertebral histiocytosis-X causing spinal cord compression. Surg Neurol 1983; 19: 369-372.

11 Padovani R, Cavallo M, Tonelli MP et al. Histiocytosis-X: a rare cause of radioculopathy. Neurosurgery 1988; 22: 1077-1079.

12 Kerr R. Eosinophilic granuloma of the spine causing neurologic deficit. Orthopedics 1989; 12: 312.

13 Acciari $\mathrm{N}$ et al. Langerhans cell histiocytosis of the spine causing cord compression: case report. Neurosurgery 1992; 31: 965-981.

14 Mirra J. Bone Tumors: Diagnosis and Treatment. JB Lippincott: Philadelphia, 1980: 376-392.

15 Casson IR et al. Eosinophilic granuloma of the cervical spine in an adult. $N$ Y State J Med 1981; 81: 1102-1104.

16 Sanchez RL, Liovet J, Moreno A, Galito E. Symptomatic eosinophilic granuloma of the spine. Orthopedics 1984; 7: 1721-1726.

17 Martin N, Helias A, Pottuz GJ, Nahum H. Localisation pedicularie cervicale isolea d'un granuloma eosinophile chez un adulte. Ann Radiol (Paris) 1985; 28: 391-393.

18 Dickinson LD, Farhat SM. Eosinophilic granuloma of the cervical spine. A case report and review of the literature. Surg Neurol 1991; 35: 57-63.

19 Kumar A. Eosinophilic granuloma of the spine with neurological deficit. Orthopedics 1990; 13: 1310-1312.

20 Mitnik JS, Pinto RS. Computed tomography in the diagnosis of eosinophilic granuloma. J Comput Assist Tomogr 1980; 4: 791-793.

21 David $\mathrm{R}$ et al. Radiologic features of eosinophilic granuloma of bone. AJR 1989; 153:1021-1026.

22 De Schepper AMA, Ramon F, Van Marck E. MR imaging of eosinophilic granuloma: report of 11 cases. Skeletal Radiol 1993; 22: 163-166.

23 Schachar NS, Edwards GE. Vertebra plana (Calve's disease) due to aneurysmal bone cyst. J Bone Joint Surg Br 1974; 56: 586.

24 Poulsen JO, Jenson JT, Thommesen P. Ewing's sarcoma simulating vertebra plana. Acta Orthop Scand 1975; 46: 211-215.

25 Ruff SJ, Taylor TKF, Nicholson DR. Eosinophilic granuloma of the spine. J Bone Joint Surg Br 66: 780.

26 O'Donnell J, Brown L, Herkowitz H. Vertebra plana-like lesions in children: case report with special emphasis on the differential diagnosis and indications for biopsy. J Spinal Disord 1991; 4: 480-485. 